\title{
Extraction and evaluation of Allium cepa for pharmacological action
}

\author{
Deepa Gupta*, Divya Lalwani and Rakesh Gupta \\ L. B. S. College of Pharmacy, Tilak Nagar, Jaipur (Rajasthan) India.
}

GSC Biological and Pharmaceutical Sciences, 2022, 18(02), 168-172

Publication history: Received on 22 December 2021; revised on 31 January 2022; accepted on 02 February 2022

Article DOI: https://doi.org/10.30574/gscbps.2022.18.2.0043

\begin{abstract}
Allium cepa L"has been reported for several biochemical constituents. The basic bioactive chemicals are quercetin, flavanols, flavanoids, sulphur compound etc. The bulb part of onion has been used for safer chemical compound that can be edible and decrease the appetite loss.

"Allium cepa L" has been used in several physiological and metabolic functions. Allium cepa L has different nutrients such as carbohydrates, sugars, dietary fibres, protein, vitamins etc. "Allium cepa L" has multiple components which is used in various formulations. Biological parts of onion has been reported for the curative and medicinal purposes such as leaves and bulb extract used to reduce platelet aggregation and diarrhea problems.

The "Allium cepa L" has functional factors useful in pharmacological activities. It has been reported to release extra fluid in excretion process. It has been also used in various biological process such as body circulation, movement of fluid etc.

"Allium cepa L" has been reported for various medicinal activities and it can be used to formulate the various pharmaceutical forms. The pharmaceutical formulations of bulb onion has been reported for several diseases. The formulations of bulb onion has been used to for varied pharmacological activities.
\end{abstract}

Keywords: Allium cepa L; Quercetin; Flavanoids; Nutraceutical

\section{Introduction}

"Allium cepa L" is edible vegetable belongs to liliaceae family. The Latin word cepa meaning onion. Allium cepa $\mathrm{L}$ has major chemical constituent such as flavonoid, flavanols, flavanones, sulphur, quercetin etc. Allium is a genus of plantae kingdom. It has various botanical characteristics beneficial in several pharmacological actions. Allium is a vegetable of monocotyledon family. "Allium cepa L" has various biological effects beneficial in curative therapy. "Allium cepa L" has been reported for various pharmacological actions. Allium has been used in bulb form for effective therapeutic and medicinal purposes. (1)

\footnotetext{
${ }^{*}$ Corresponding author: Deepa Gupta

L. B. S. College Of Pharmacy, Tilak Nagar, Jaipur (Rajasthan) India.

Copyright $@ 2022$ Author(s) retain the copyright of this article. This article is published under the terms of the Creative Commons Attribution Liscense 4. 0.
} 


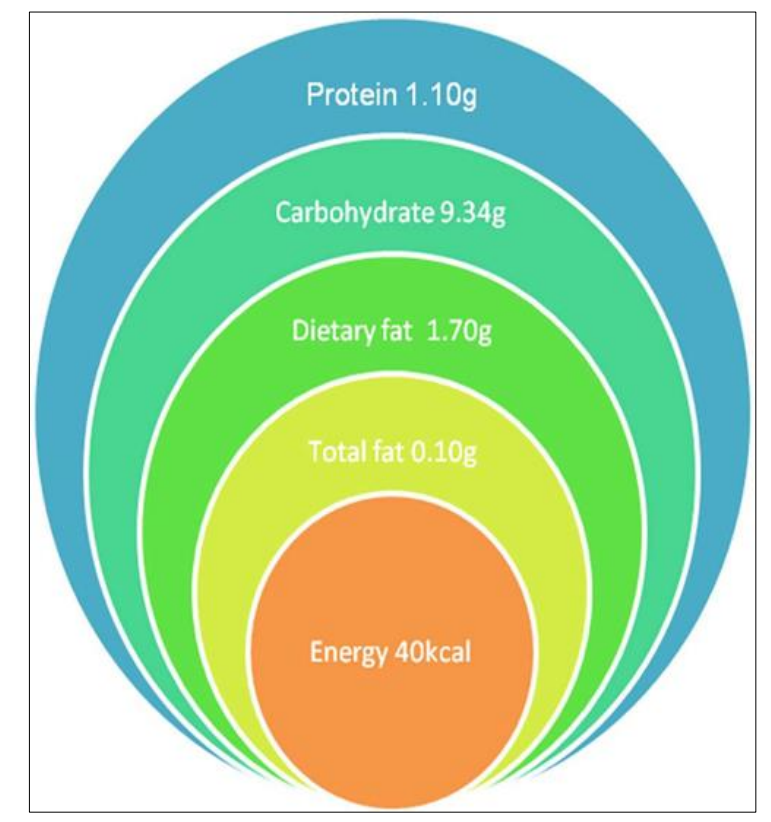

Figure 1 Nutritive values in "Allium cepa L" (2)

The bulb part of "Allium cepa L" has high nutritive value. The bulb onion has been reported with various pharmaceutical formulations. The bulb part of onion is full of nutritive value and it has phytochemical importance such as quercetin, flavones, 4 -flavanols etc.

The Allium cepa L has been used for different pharmacological actions such as anticancer, ant thrombosis, antidiabetic etc. It has been reported for antimicrobial culture used in various bacterial diseases. The "Allium cepa L" has been used to formulate various pharmaceutical formulations. The main role of bulb onion is to initiate the process of medicative purposes. Onion has been used in varied pharmacological actions, to reduce the dehydration, etc. The main characterstics of onion are nutraceutical, highly therapeutic and used to treat various diseases.

"Allium cepa L" extract has been used in various activities. The main flavanoids as bioactive constituents present in the bulb part of onion which can be used in extract form. (3) Extract of onion has quercetin chemical compound with highly effective medicinal and therapeutic actions. Soxhlet extraction method has been used to extract the main phytochemical constituents.

Bioactive chemical compounds extracted from the bulb part of "Allium cepa L". It has been used in the various pharmaceutical formulations. The various onion components has been isolated from the extract of "Allium cepa $\mathrm{L}$ " such as allicin, acetic acid, catechol, allyl sulphides, etc. These components of onion has been reported for several biological and pharmacological activities, such as quercetin has been used for anticancer, antioxidant, wound healing, antimutagenic, allergenic reactions etc. Extract of "Allium cepa L" is used for different medicinal purposes. The extraction can be carried out by using Soxhlet Apparatus. (4)

Extraction involves:

- Collection of crude drugs

- Selection of solvent

- Condensation

- Evaporation of solvent

- Collection of products 


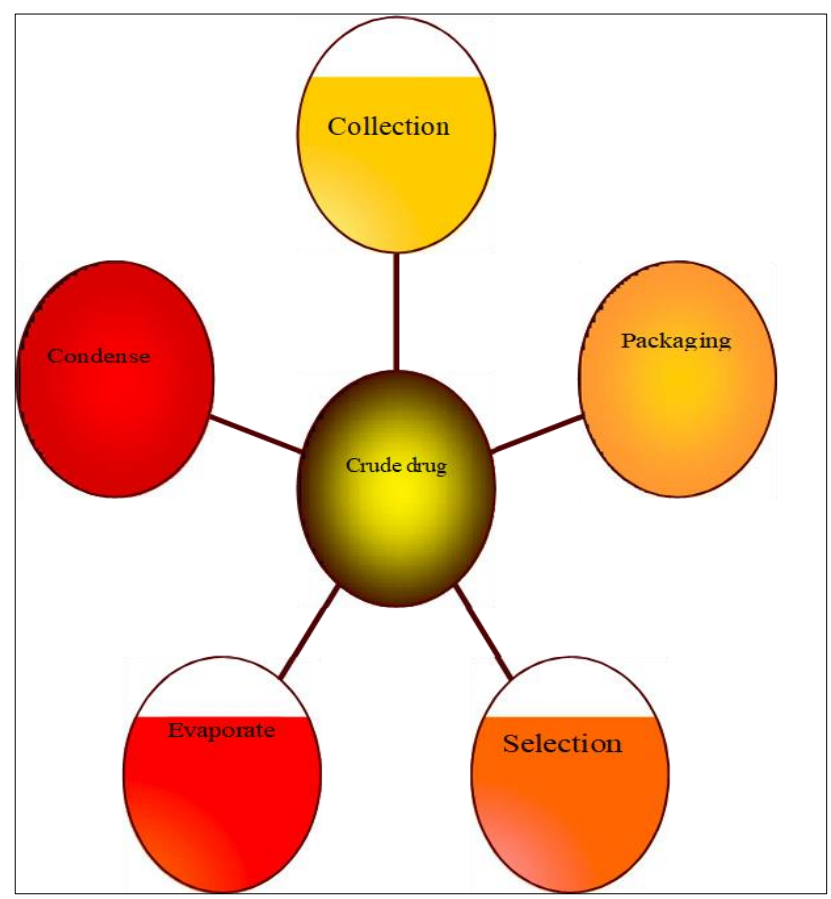

Figure 2 Extraction

\section{Procedure}

\subsection{Extraction procedure}

The scales of "Allium cepa L" were collected and dried in shade. Dried sample was packed in thimble (Filter paper). Sample was mixed with condensed ethanol. Extract was collected. Further, recycle was done and product was collected. It was then evaporated and final product was collected.

Physicochemical characterization of the extract

\subsection{Physical Appearance}

A small quantity of extract was taken on butter paper and viewed well illuminated.

\subsection{Color and odor}

It was evaluated for organoleptic properties such as, color and odor.

\subsection{Boiling point}

The boiling point of extract was determined by boiling point apparatus.

\subsection{Solubility}

Solvent such as ethanol, water, hydrochloric acid, $0.01 \mathrm{~N}$ sodium hydroxide, etc. were used for solubility studies. This study includes selection of suitable solvent to dissolve the pure drug as well as excipients. They may indirectly help in preliminary evaluation of a substance.

\subsection{TLC determination}

Stationary phase - Silica gel G (Rp-18)

Mobile phase-THF: Water: Formic acid: 40: 60: 6

Detector- UV Chamber 


\subsubsection{Procedure}

The slurry of silica gel G was prepared and thin layer uniformly coated on a glass plate. The plate was dried in hot air oven. The mobile phase was prepared in the ratio of THF : Water : Formic acid (40:60:6) and added to TLC chamber. The two spots of sample and reference were applied on the plate. The plate was inserted into the TLC chamber.

Rf value was determined and calculated.

\subsection{Chemical analysis of the extract}

- Different portion of the extract were taken in 7 test tubes. Different solvents were added in the above test tubes such as water, ethanol, ether, glycerol etc. The test tubes were observed for the results.

- Extract was measured accurately $10 \mathrm{ml}$ and added in the sample test tube. $10 \mathrm{ml}$ of sodium hydroxide was measured and added into the above test tube. The test tube were observed for the results.

- Extract was measured accurately $10 \mathrm{ml}$ and mixed with $10 \mathrm{ml}$ of water to make an aqueous solution in the test tube. Then to this solution $5 \mathrm{ml}$ ammonia was added in the above test tube. Separately, $10 \mathrm{ml}$ concentrated $\mathrm{H}$ 2SO 4 was diluted with water. This was then added into the above aqueous solution. The test tube were observed for the result.

\section{Result and Discussion}

Physicochemical characterization of the extract

\subsection{Physical appearance}

Extract was homogeneous and translucent clear liquid and easily dispersable in water, ethanol and glycerol.

\subsection{Color and odor}

Colour of extract was slightly pink and pungent odor.

\subsection{Boiling point determination}

The boiling point of extract was found to be 110 o $\mathrm{C}$ using theist tube apparatus.

\subsection{Solubility of the extract}

The solubility of the extract was carried out with different solvents. Extract was easily soluble in water, glycerol and ethanol.

Table 1 Solubility of extract using various solvents

\begin{tabular}{|l|l|l|}
\hline S. No. & Solvents & Inference \\
\hline 1 & Water & Very soluble \\
\hline 2 & Ether & Soluble \\
\hline 3 & Glycerol & Soluble \\
\hline 4 & Ethanol & Sparingly soluble \\
\hline
\end{tabular}

\subsection{TLC determination}

The Thin layer chromatography was performed using extract of "Allium cepa L". The Rf value was found to be 0.63 .

\subsection{Chemical test analysis of the extract}

\subsection{Extract was treated with different chemicals and result mentioned}

- Extract was treated with sodium hydroxide and yellow clear liquid was obtained.

- Further, extract was treated with ammonia and clear yellow colour liquid was obtained confirming presence of quercetin in the extract. 
- Quercetin was confirmed further with sulphuric acid. Extract was treated with concentrated H 2SO4 and dark yellow color clear liquid was obtained indicating quercetin was present in the extract.

Table 2 Chemical analysis of the extract

\begin{tabular}{|l|l|l|}
\hline S. No. & Solvents used & Inference \\
\hline 1 & Water & Pale yellow \\
\hline 2 & Glycerol & Colorless \\
\hline 3 & Ethanol & Colorless \\
\hline 4 & Ether & Colorless \\
\hline
\end{tabular}

Table 3 Quercetin analysis of the extract

\begin{tabular}{|l|l|l|}
\hline S. No. & Chemical used & Inference \\
\hline 1 & Sodium hydroxide & Pale yellow \\
\hline 2 & Ammonia & Yellow color \\
\hline 3 & Concentrated H2SO4 & Dark yellow color \\
\hline
\end{tabular}

\section{Conclusion}

"Allium cepa L" is used to formulate various pharmaceutical formulations such as cream, oil, shampoo forms are available in the market preparations. Extract of onion has been isolated from its bulb part and it's highly effective in varied metabolic reactions. The bulb part of onion has many phytochemical constituents useful in therapeutic and medicinal activities. The main bioactive contents are flavanoid, sulphur, allyl-sulphides, quercetin and allicin etc. These chemical constituents are highly effective in the chemopreventive, respiratory and rejuvenation of hair. There are several pharmacological actions such as antihypertensive, antidiabetic, anticoagulation, potent hair rejuvenation etc. In this "Allium сера L "extract has been isolated from its bulb part which is highly used for the nutraceutical, pharmaceutical and therapeutic activities.

\section{Compliance with ethical standards}

\section{Disclosure of conflict of interest}

There is no conflict of interest.

\section{References}

[1] Pareek S, Sharma S; “Onion (Allium cepa L)”,Department of Agriculture and environmental sciences ;National institute of food technology, Kundli ,Sonipat , Haryana ,India ,May 2017 ;(1145 - 1161).

[2] Mitra J ,Rao P.S ; “Onion dehydration :A Review : The Journal of food sciences and technology ;Mysore ,India ,2012 ;(267-277).

[3] Shikafi SA, Dauda H, "Antibacterial activity of (Allium cepa L) on some pathogenic bacteria, associated with ocular infections", The Department of microbial technology. 2013; 47-51.

[4] Barry S, Kendler; "Garlic (Allium sativum) and Onion (Allium cepa L): A review of their relationship to cardiovascular disease", The Journal of Preventive Medicine. 1987; 670-685.

[5] Kumar S, Bhowmik D ; "A traditional medicinal herb and its health benefits”, The Journal of chemical and pharmaceutical research ;Uttar Pradesh :India ,2010, 283 -291). 